\title{
DESAIN PEMBELAJARAN MODEL ASSURE BERBASIS MULTIMEDIA PADA MATA PELAJARAN AL-QUR'AN HADITS
}

\author{
Ahmad Muzakki', Husniyatus Salamah Zainiyati, ${ }^{2}$ \\ Dani Cahyani Rahayu ${ }^{3}$, Husnul Khotimah ${ }^{4}$ \\ Pascasarjana UIN Sunan Ampel Surabaya \\ email:zakki.f35@gmail.com
}

\begin{abstract}
ABSTRACK
The purpose of writing this article is to achieve a learning design that is by planning, effective and efficient learning. As information technology develops, it is hoped that teachers can take advantage of multimedia technology in the learning process. Also, through this paper, it is hoped that teachers can design learning effectively and efficiently, through the Assure learning model. In writing this article using a qualitative descriptive method, describing the design of the multimedia-based Assure learning model. The results showed that the use of the multimedia-based Assure model could increase learning variation and increase student learning motivation, by analyzing student characteristics, learning styles, selecting appropriate methods, media, and teaching materials, and involving students actively in learning.
\end{abstract}

Keyword: Learning Al-Quran Hadith, Assure Model, Multimedia

\section{ABSTRAK}

Tujuan dari penulisan artikel ini adalah tercapainya desain pembelajaran yang sesuai dengan perencanaan, pembelajaran yang efektif dan efisien. Seiring dengan berkembangnya teknologi informasi, diharapkan guru bisa memanfaatkan teknologi multimedia dalam proses pembelajaran. Selain itu melalui tulisan ini, diharapkan guru bisa mendesain pembelajaran dengan efektif dan efisien, melalui model pembelajaran Assure. Dalam penulisan artikel ini menggunakan metode deskriptif kualitatif, dengan mendeskripsikan desain model pembelajaran Assure berbasis multimedia. Hasil penelitian menunjukkan bahwa penggunaan model Assure berbasis multimedia ini bisa menambah variasi pembelajaran dan meningkatkan motivasi belajar siswa, dengan menganalisis karakteristik siswa, gaya belajar, pemilihan metode, media dan bahan ajar yang sesuai, serta melibatkan siswa secara aktif dalam pembelajaran.

Kata kunci: pembelajaran Al-Qur'an Hadits, model Assure, multimedia 


\section{A. PENDAHULUAN}

Pembelajaran adalah suatu proses interaksi timbal balik antara guru dengan siswa. Proses pembelajaran akan berjalan dengan baik manakala dua aspek tersebut dapat berinteraksi dengan baik, guru menyampaikan materi pembelajaran, dan siswa mendengarkan apa yang diterangkan oleh guru, tidak terkecuali pada pembelajaran mata pelajaran Al-Qur'an Hadits.

Tetapi, tidak semua pembelajaran dapat berjalan dengan kondusif, begitu juga tidak semua siswa bisa menangkap dengan baik apa yang diterangkan oleh guru, karena pada dasarnya setiap siswa mempunyai gaya belajar yang berbeda. Ada siswa yang mempunyai gaya belajar dengan iringan musik, ada juga siswa yang mempunyai gaya belajar dengan melalui tayangan audio visual. Richard Bandler, John Grinder dan Michael Grinder dalam karyanya Neuro Linguisitc Programming mengemukakan bahwa manusia secara umum memiliki ciri belajar yang dominan, yakni Visual, Auditori dan Kinestetik (Luk Luk Nur Mufidah, 2017: 246-259). Gaya belajar adalah cara termudah siswa dalam menyerap informasi dari guru, oleh karena itu, gaya belajar yang sesuai adalah kunci dari keberhasilan siswa dalam belajar (Josua Bire Arylien Ludji Bire, 2014).
Hasil penelitian yang dilakukan di SMK Negeri 5 Kupang pada tahun pelajaran 2013/2014, secara simultan maupun terpisah, gaya belajar visual, auditorial dan kinestetik mampu mempengaruhi hasil belajar siswa (Josua Bire Arylien Ludji Bire, 2014).

Dari paparan di atas dapat disimpulkan bahwa pentingnya penggunaan gaya belajar yang sesuai, untuk meningkatkan hasil belajar siswa. Bagi siswa pentingnya mengenal karakteristik belajar mereka, sedangkan bagi guru, pentingnya memahami gaya belajar siswa untuk mencapai hasil belajar yang memuaskan.

Pentingnya penggunaan multimedia dalam proses pembelajaran adalah salah satu upaya dalam mengembangkan suatu proses pembelajaran yang lebih menarik, dan memudahkan siswa dalam menangkap informasi dari guru. Karena multimedia pada dasarnya sudah mengcover karakteristik gaya belajar siswa secara umum. Selain itu, pembelajaran berbasis multimedia juga mempengaruhi motivasi belajar siswa. Multimedia juga membawa pengaruh positif yang signifikan terhadap hasil belajar siswa (Galuh Kartikasari, 2016).

Pada pembelajaran PAI, khususnya mata pelajaran Al-Qur'an Hadits, pada umumnya cenderung monoton, tanpa 
adanya variasi dalam pembelajaran yang membuat suasana kelas lebih hidup. Oleh karena itu, pentingnya penggunaan multimedia dalam pembelajaran PAI khusunya mata pelajaran Al-Qur'an Hadits agar lebih menarik dan membuat siswa tidak hanya mendengarkan saja, tetapi lebih aktif dalam belajar.

Ada beberapa kelebihan penggunaan multimedia dalam pembelajaran, khususnya mata pelajaran Al-Qur'an Haditts yaitu dapat meningkatkan motivasi siswa, membuat pembelajaran lebih menarik, bermanfaat bagi siswa yang agak lamban dalam menangkap materi. Hasil penelitian yang dilakukan di MAS Miftahussalam Demak, bahwa penggunaan multimedia dapat meningkatkan keaktifan siswa dalam belajar di kelas (Ahmad Taufik, Universitas Wahid, and Hasyim Semarang, 2019).

Sementara pada pembelajaran AlQur'an Hadits berbasis multimedia, perlunya mendesain model pembelajaran terlebih dahulu, agar proses pembelajaran sesuai dengan petunjuk dan tujuan pembelajaran itu sendiri. Pada model pembelajaran ASSURE itu sendiri adalah sebuah model desain pembelajaran sederhana, yang menjadikan pembelajaran lebih efektif, efisien dan menarik (Tessa Qoriah Rasidi, 2016). Hasil penelitian yang dilakukan oleh Widia Maya Sari dan
Endang Susiloningsih (2015), bahwa penerapan model pembelajaran ASSURE dapat meningkatkan daya berpikir siswa lebih kritis, dibandingkan dengan pembelajaran model yang biasanya dipakai oleh guru (Endang Susiloningsih Widia Maya Sari, 2015: 1468-1477). Selanjutnya model pembelajaran mode ASSURE dapat dijadikan sebagai alternatif pembelajaran, dimana guru bisa mempersiapkan rencana pembelajaran dengan menganalisis karakteristik siswa, merumuskan tujuan pembelajaran dan kompetensi siswa, serta menentukan metode, materi dan media pembelajaran yang sesuai (Rasidi, 2016).

Selain itu, pentingnya keahlian guru dalam memanfaatkan multimedia, agar pembelajaran bisa dikemas dengan menarik dan interaktif. Akan tetapi, kebanyakan guru masih gagap teknologi tertutama penggunaan multimedia dalam pembelajaran, hal ini yang menjadi penghambat dalam pemanfaatan multimedia. Perlu ditekankan pentingnya menggunakan multimedia dalam pembelajaran dengan menggunakan model ASSURE, agar siswa tidak bosan dalam belajar yang kebanyakan masih menggunakan metode yang monoton.

Dari paparan di atas, penulis menekankan kepada guru bahwa pentingnya mendesain model pembelajaran 
ASSURE berbasis multimedia pada mata pelajaran Al-Qur'an Hadits demi keefektifan dan efisiensi pembelajaran.

\section{B. TINJAUAN PUSTAKA}

Model pembelajaran ASSURE merupakan model pembelajaran yang sederhana. Hal ini disebabkan karena pada pembelajaran model ASSURE didesain dengan terperinci, mulai dari menganalisis karakteristik siswa, merumuskan tujuan pembelajaran, penyajian materi, menilai tingkat pemahaman siswa, keterlibatan siswa dalam pembelajaran, dan evaluasi (Widia Maya Sari, 2016). Sedangkan Pribadi (2011) menyatakan bahwa pembelajaran model ASSURE adalah singkatan dari Analyze learner characterictics, State performance objective, Select (methods, media dan material), Utilize materials, Require learner participation, Evaluation and revise (Pribadi, 2011). Selanjutnya Dali (2011) mengemukakan bahwa ASSURE adalah model pembelajaran yang bertujuan untuk membangunkan courseware pembelajaran melalui asas yang kukuh (Dali, 2011: 1-8).

Sedangkan multimedia sendiri merupakan sarana yang dapat dimanfaatkan sebagai media menyalurkan informasi dan pesan, untuk menstimulus pikiran, semangat dan perhatian siswa, guna mendorong kemauan belajar siswa (Nanang Gesang Wahyudi, Sri Anitah, and Muhammad Akhyar, 2016: 10-12). Hackbarth mengemukakan bahwa multimedia adalah gabungan dari beberapa media guna mempermudah dalam menyampaikan informasi berupa teks, audio maupun video (S. Hacbarth, 1998). Selanjutnya Philip (1997) berpendapat bahwa multimedia merupakan gabungan dari beberapa media yakni teks, audio dan video yang kemudian dimasukkan ke dalam suatu program (R. Phillips, 1997).

Berdasarkan pendapat dari beberapa ahli, dapat disimpulkan bahwa multimedia adalah gabungan dari beberapa media yang meliputi teks, audio dan video yang dimasukkan ke dalam suatu program, guna mempermudah dalam penyampaian suatu informasi dan mengemas informasi agar lebih menarik dan mudah dipahami. Sementara model ASSURE merupakan model pembelajaran yang dirancang untuk menciptakan pembelajaran yang efektif dan efisien, dengan melalui beberapa tahap, yakni menganalisis karakteristik siswa, perumusan tujuan pembelajaran, pemilihan metode dan media. 


\section{METODE PENELITIAN}

Panulisan artikel ini, metode pengumpulan data yang digunakan adalah dokumentasi, dengan menggunakan pendekatan kualitatif. Sedangkan dalam menganalisis data dan metode yang digunakan adalah kualitatif. Analisis data kualitatif enurut Bogdan dan Biklen, yang dikutip oleh Moeloeng (2013) merupakan upaya jalan bekerja dengan data, pengorganisasian data, memilah dan memilih menjadi satuan yang dapat dikelola, serta mencari dan menemukan pola yang penting dan yang dipelajari (J. Moleong, L., 2013).

Penulis menggunakan analisis data kualitatif dengan tujuan untuk mendeskripsikan tradisi dan menafsirkan fenomena yang terjadi dalam penggunaan media pendidikan sebagai salah satu komponen implementasi sistem pendidikan Islam di awal penyebarannya.

\section{PEMBAHASAN}

\section{Model Pembelajaran ASSURE}

Pembelajaran adalah suatu proses kegiatan dengan tujuan untuk mengubah tingkah laku siswa oleh guru dengan sistematis, atau intraksi antara individu sehingga dapat menghasilkan perubahan seorang ataupun lingkungan secara positif (Saihu, 2019: 71). Pembelajaran secara formal biasanya dilakukan di sekolah berdasarkan perangkat pembelajaran, media dan instrumen penilaian. Sementara itu, model pembelajaran terus berkembang dari tahun ke tahun. Para ahli pendidikan terus mengembangkan beberapa model pembelajaran, demi menunjang kualitas pendidikan. Salah satunya adalah model ASSURE. Sedangkan ASSURE adalah singkatan dari Analyze learner characterictics, State performance objective, Select (methods, media dan material), Utilize materials, Require learner participation, Evaluation and revise.

Analyze learner (analisa siswa). Sebelum memulai pembelajaran, terlebih dahulu guru menganalisis siswa mengenai karakter, gaya belajar dan sikap siswa dalam belajar. Kaitannya dengan gaya belajar siswa, terdapat tiga jenis gaya belajar siswa, yakni visual, auditory dan kinestetik. Gaya belajar visual mengandalkan indera penglihatan yang mana siswa akan lebih mudah menangkap informasi melalui gambar. Dan yang kedua auditory, gaya belajar dengan mengandalkan indera pendengaran, dimana siswa lebih mudah menangkap materi dengan bantuan atau iringan musik, misalnya siswa belajar dengan diiringi musik, atau guru mengajar dengan cara 
dinyanyikan. Dan kinestetik, yakni mengandalkan gerakan tubuh. Dengan memahami siswa melaui ketiga gaya belajar tadi, maka pembelajaran akan berjalan dengan efektif dan efisien.

Stating objectives (menyatakan tujuan). Menetapkan tujuan pembelajaran pada materi yang akan diajarkan kepada siswa, akan membuat siswa memahami perubahan perilaku bagaimana yang diharapkan oleh guru kepada siswa. Beberapa hal penting yang harus dilakukan oleh guru ketika menyusun rencana pembelajaran, yakni menetapkan tingkah laku sehari-hari yang merefleksikan materi ke dunia nyata. Dan tujuan khusus, guna menjelaskan luaran pada suatu proses pembelajaran, wujud luaran dari tujuan khusus dijabarkan menggunakan format ABCD. ABCD adalah format untuk menjelaskan tujuan khusus pembelajaran, sedangkan singkatan dari ABCD adalah: Audience (siswa), dalam konteks ini siswa diminta oleh guru untuk memperagakan perubahan tingkah laku setelah kegiatan belajar selesai. Behavior (tingkah laku) kemampuan yang harus ditunjukkan oleh siswa kepada guru setelah proses pembelajaran selesai. Condition (kondisi), bagaimana siswa memperagakan tingkah laku yang telah ditetapkan dalam rencana pembelajaran. Degree (derajat) level yang diharapkan yang mana siswa setidaknya bisa memperagakan perubahan perilaku yang sudah dilakukan dalam pembelajaran.

Select methods, media and materials. Setelah guru mengetahui karakter siswa, gaya belajar dan tingkah laku dalam belajar, selanjutnya guru memilih metode media dan bahan ajar yang disesuaikan dengan karakteristik siswa tersebut, agar pembelajaran bisa berjalan dengan efektif dan efisien. Metode pembelajaran yang baik adalah metode yang sesuai dengan karakter belajar siswa, demi menunjang pembelajaran. Sedangkan media digunakan untuk membantu guru dalam mencapai tujuan belajar secara maksimal. Terdapat banyak media yang bisa dimanfaatkan guru untuk pembelajaran, yakni teks, gambar, video, audio dan multimedia komputer. Dan materi pembelajaran. Materi pembelajaran dapat membantu peserta didik guna mencapai tujuan pembelajaran. Materi pembelajaran bisa berupa software dan hardware. Software adalah program perangkat lunak yang dapat dimanfaatkan oleh guru untuk menunjang pembelajaran, seperti Microsoft powerpoint, program animasi dan program pemutar video. Sedangkan hardware perangkat keras yang dapat dimanfaatkan untuk membantu penggunaan software, seperti komputer, LCD proyektor, TV dan DVD. 
Utilize method, media and materials. Setelah tahap memilih metode, media dan bahan ajar, maka langkah selanjutnya adalah penggunaan metode, media dan bahan ajar. Sementara itu, yang harus dilakukan oleh guru dalam menggunakan metode, media dan bahan ajar adalah preview materi yang akan digunakan guru untuk pembelajaran jangan menggunakan sesuatu di kelas dimana guru tidak pernah melakukan pengecekkan secara keseluruhan, artinya sebelum menggunakan sesuatu, hendaknya guru mengecek terlebih dahulu mengenai kesiapannya. Menyiapkan bahan ajar, guru harus yakin bahwa dia memiliki sesuatu apa yang dibutuhkan oleh siswa dan menyiapkan ruangan kelas, yang mana kegiatan pembelajaran akan dilakukan oleh guru akan berjalan dengan baik. Menyiapkan siswa, guru menunjuk siswa menjadi overview dan menjelaskan bagaimana dia memperoleh informasi yang disampaikan oleh guru. Menyiapkan pengalaman beajar, kecakapan guru dalam memainkan situasi adalah tugas dari guru. Kegiatan pembelajaran adalah suatu pengalaman.

\section{Require learner participation} (menuntut partisipasi siswa). Pada tahap ini guru hendaknya melibatkan siswa secara aktif dalam pembelajaran, agar pembelajaran bisa berjalan dengan maksimal. Guru juga harus menguraikan apa yang diinginkan kepada siswa untuk terlibat di kelas, seperti kerja kelompok, kelompok presentasi dan diskusi. Dan guru hendaknya menghindari ceramah sepanjang sesi pembelajaran. Mempersilahkan siswa untuk tanggap berpendapat.

Evaluate and revise (evaluasi dan revisi). Tahap terakhir ini sering diabaikan oleh guru, padahal pada tahap inilah guru bisa mengetahui sejauhmana keberhasilan dalam mengajar. Pada tahap ini, yang harus dilakukan oleh guru adalah mengevaluasi performance siswa, mengevaluasi efektifitas penggunaan komponenkomponen media pembelajaran yang digunakan, mengevaluasi performance guru ketika melakukan pembelajaran dan melakukan revisi dari kelemahankelemahan yang diidentifikasi dalam pembelajaran.

\section{Multimedia}

Multimedia berasal dari dua kata, yakni multi dan media. Kata multi berarti lebih dari satu, sedangkan kata media (latin) berarti perantara, yang secara keseluruhan dapat disimpulkan bahwa multimedia berarti beberapa perantara, dalam hal ini berarti perantara dalam bentuk teks, audio dan visual. Sedangkan Heinich, dkk (1982) mengartikan istilah media sebagai "The term allude to whatever conveys data 
between a source and a beneficiary". Sedangkan pembelajaran adalah suatu proses ilmu/pengetahuan dari pendidik kepada peserta didik. Dengan melihat pengertian dari media dan multiedia tersebut, maka dapat disimpulkan bahwa media pembelajaran adalah sarana/wahana untuk menyalurkan informasi/ilmu dari pendidik kepada peserta didik.

Media adalah salah satu jenis dari media pembelajaran. Namun, Definisi sight and sound memang belum jelas. Namun secara sederhana dapat diartikan sebagai lebih dari satu media. Didalam multimedia terdapat penggabungan antara media sound, visual, slide bergambar dan bersuara, animasi, dan lain-lain. Melihat dari ciri-ciri tersebut maka secara umum dapat didefinisikan bahwa multimedia adalah berbagai macam kombinasi grafik, teks, suara, video dan animasi. Penggabungan ini merupakan satu kesatuan yang secara bersama-sama menampilkan informasi, pesan, atau isi pelajaran. Sistem pembelajaran media merupakan teknologi yang melibatkan teks, gambar, suara, dan video yang diintegrasikan dalam penyajian materi yang diajarkan pada siswa. Dengan menggunakan sistem pembelajaran berbasis mixed media dapat menciptakan suasana belajar mengajar yang menyenangkan dan interaktif sehingga dapat menambah motivasi siswa selama proses belajar mengajar berlangsung yang dapat mendorong penyerapan materi menjadi lebih ideal. Media yang dapat digunakan dalam pembelajaran berbasis multimedia ini adalah sound, slide suara, multimedia dan e-learning.

Kemampuan media ini adalah suatu kemampuan menggabungkan antara teks, gambar, sound, musik, animasi gambar atau video dalam satu kesatuan yang mampu mendukung tercapainya tujuan pembelajaran. Dengan demikian, materi yang disajikan akan semakin menarik dan dapat menimbulkan feedback yang positif dari siswa karena mereka akan semakin termotivasi dalam belajar sehingga materi yang diajarkan dapat dengan mudah dicernanya. Penggunaan komputer multimedia dalam proses pembelajaran mempunyai tujuan meningkatkan mutu pembelajaran dan pembelajaran itu sendiri. Jenis peralatan yang dipakai dalam mixed media ini diantaranya: komputer, video kamera, VCR, Overhead Projector, multivision atau sejenisnya, CD Player, dan CD. Sebenarnya CD player merupakan peralatan tambahan (External Peripheral) komputer, namun sekarang sudah menjadi bagian unit komputer tertentu.

Berdasarkan pemaparan di atas, dapat diambil kesimpulan bahwa yang dimaksud 
dengan multimedia pembelajaran ialah berbagai macam kombinasi grafik, teks, suara, video, dan animasi yang menjadi satu kesatuan yang dapat digunakan dalam mencapai tujuan pembelajaran.

Desain pembelajaran multimedia pada mata pelajaran Al-Qur'an Hadits ini sangatlah penting, hal ini karena orientasi jangka panjang yang diharapkan pada software perlu dipertimbankan agar seimbang antara pembuatan dan pemakaian. Pendesainan programming ini harus melihat perkembangan zaman dan subyeknya atau pemakainya, sehingga desain akan semakin menarik minat pengguna serta memotivasi pengguna untuk mempelajarinya.

Dengan mempertimbangkan hal demikian, maka di dalam buku Srategi Pembelajaran Sekolah Berstandar Internasional dan Nasional yang mengutip pendapat dari Simon dan Thompson yakni ada tiga jenis tipe programming interactive media, yakni Functional Design, Physical Design dan Logical Design. Ketiga tipe ini memiliki kekhususan sendiri-sendiri.

\section{Desain Model Pembelajaran ASSURE Berbasis Multimedia Mata Pelajaran Al-Qur'an Hadits}

a. Analyze Learner Characteristic (Analsis Karakteristik Siswa)

Sebelum melakukan pembelajaran Al-Qur'an Hadits, terlebih dahulu guru menganalisis karakterisik siswa secara umum, berikut contoh hasil analisis karakteristik siswa ditinjau dari kemampuan pemahaman materi:

\begin{tabular}{|c|c|c|c|}
\hline Kelas & $\begin{array}{c}\text { Jumlah } \\
\text { Siswa }\end{array}$ & $\begin{array}{c}\text { Kemampuan } \\
\text { Rata-rata }\end{array}$ & $\begin{array}{c}\text { Krieria } \\
\text { Ktuntasan } \\
\text { Minimal }\end{array}$ \\
\hline X & 25 & 75 & 80 \\
\hline XI & 20 & 60 & 80 \\
\hline XII & 25 & 75 & 80 \\
\hline
\end{tabular}

Dari tabel diatas, dapat disimpulkan bahwa rata-rata nilai siswa belum memenuhi kriteria ketuntasan minimal (KKM), tingkat pemahaman siswa akan materi Al-Qur'an Hadits juga masih rendah.

Selain itu, gaya belajar siswa juga bermacam-macam. Sebagian siswa lebih mudah faham ketika belajar dengan bantuan audio, ada juga yang memiliki gaya belajar dengan bantuan visual, yakni dengan menayangkan gambar. Karena siswa mempunyai gaya belajar yang berbeda, maka guru mengajar dengan menggunakan bantuan audio visual, yang mana guru menayangkan materi berbentuk video pembelajaran AlQur'an Hadits.

b. State performance objective (menentukan Tujuan Pembelajaran) 
Selanjutnya masuk pada tahap menentukan tujuan pembelajaran secara spesifik, agar siswa mampu mengamati perilaku yang harus ditampilkan dalam kehidupan sehari-hari sebagai bagian dari implementasi pembelajaran AlQur'an Hadits.

Kondisi sebagaimana tersebut akan meliputi pengguanaan teknologi dan media dalam menilai pencapaian dari tujuan belajar.

Tujuan pembelajaran

Berikut contoh tujuan pembelajaran Al-Qur'an Hadits, yang tertuang dalam rencana pembelajaran:

1) Menyajikan materi tentang kemukjizatan Al-Qur'an

2) Mencintai Al-Qur'an

3) Menjelaskan tentang kemukjizatan Al-Qu'ran

4) Menyampaikan contoh-contoh kemukjizatan Al-Qur'an

c. Select (methods, media dan materials)

Karena rata-rata siswa mempunyai gaya belajar yang berbeda, maka guru dituntut untuk memilih metode, media dan bahan ajar yang tepat dan sesuai, agar pembelajaran di kelas bisa berjalan dengan maksimal, efektif dan efisien.
Pada contoh diatas, rata-rata siswa mempunyai gaya belajar dengan bantuan audio dan visual, maka guru dapat melakukan proses pembelajaran secara audio visual (video) bantuan layar LCD proyektor dan speaker.

Dari hasil pemilihan media yang tepat, selanjtunya guru memilih bahan ajar, yang dapat menunjang media pembelajaran yang dipakai untuk proses pembelajaran. Karna media yang akan digunakan berupa perangkat audio visual, maka guru merumuskan bahan ajar yang sesuai dengan media yang dipilih, yakni berupa video pembelajaran, bisa bersumber dari youtube dan internet.

d. Utilize materials

Setelah tahap pemilihan metode, media dan bahan ajar, langkah selanjutnya yakni menerapkan metode, media dan bahan ajar ke dalam proses pembelajaran. Adapun tahap implementasi metode, media dan bahan ajar meliputi: Planning (perencanaan), organizing (pengorganisasian), actuating (pelaksanaan). 


\section{e. Require learner participation}

Tahap ini, guru melibatkan siswa untuk berpartisipasi dalam proses pembelajaran, dalam rangka menumbuhkan motivasi belajar siswa. Secara psikologi ketika siswa terlibat aktif dalam pembelajaran, maka secara tidak langsung akan meningkatkan motivasi belajar mereka. Selain itu, partisipasi aktif siswa juga menciptakan pembelajaran yang efektif. Misalnya, pembelajaran kelompok diskusi pada pembelajaran alQur'an Hadis, dimana siswa mendiskusikan materi Al-Qur'an Hadits yang diberikan oleh guru.

\section{f. Evaluation and revise}

Tahap terakhir yang harus dilakukan oleh guru adalah tahap evaluasi dan revisi. Setelah guru melakukan proses pembelajaran Al-Qur'an Hadits dengan beberapa tahap di atas, maka langkah selanjutnya guru mengevaluasi hasil pembelajaran. Evaluasi pembelajaran meliputi, kekurangan dan kendala selama proses pembelajaran berlangsung yang selanjutnya dilakukan proses revisi, untuk perbaikan proses pembelajaran ke depan yang lebih baik lagi.

\section{E. KESIMPULAN}

Dari pembahasan di atas, dapat disimpulkan bahwa pembelajaran adalah suatu proses kegiatan dengan tujuan untuk mengubah tingkah laku siswa oleh guru dengan sistematis. Sedangkan model pembelajaran ASSURE adalah singkatan dari Analyze learner characterictics, State performance objective, Select (methods, media dan material), Utilize materials, Require learner participation, Evaluation and revise. Yakni proses desain model pembelajaran dari menganalisis karakter siswa, cara belajar, memilih dan menerapkan metode, media pembelajaran yang tepat dan melakukan evaluasi serta revisi selama pembelajaran berlangsung.

Sedangkan dalam mendesain pembelajaran berbasis multimedia perlu menyesuaikan perkembangan zaman, agar proses pembelajaran menjadi lebih menarik dan siswa semakin termotivasi dalam mengikuti proses prmbelajaran mata pelajaran Al-Qur'an Hadits.

\section{DAFTAR PUSTAKA}

Arylien Ludji Bire, Uda Geradus, Josua Bire. (2014). Pengaruh Gaya Belajar Visual, Auditorial Dan Kinestetik Terhadap Prestasi Belajar Siswa. Jurnal Pendidikan, 44(2).

Baharun, Hasan. (t.t.). Pengembangan Media Pembelajaran PAI Berbasis Lingkungan Melalui Model ASSURE. (n.d.). 
Dali. (2011). Rasional Ciri-Ciri Reka Bentuk Instruksional Model ASSURE dalam Penggunan Courseware Pengajaran dan Pembelajaran. Jurnal Penelitian Sultan Idris Education University, 1(2): 1-8.

Elya, Monica Hotma. (2020). Jurnal Obsesi $\square$ : Jurnal Pendidikan Anak Usia Dini Pengaruh Metode Bercerita dan Gaya Belajar Terhadap Kemampuan Berbicara Anak Usia Dini Abstrak. Jurnal Obsesi $\square$ : Jurnal Pendidikan Anak Usia Dini, 4(1): 302-315.

Hacbarth, S. (1996). The Educational Technology Handbook. New Jersey. Educational Technology Publications Inc.

Ismail, Ali, and Surya Gumilar. (2019). Implementasi Model Pembelajaran Berbasis Multimedia Interaktif Untuk Meningkatkan Hasil Belajar dan Keterampilan Berfikir Kritis Siswa. Jurnal PETIK, 5 no. September: 9-17.

Kartikasari, Galuh. (2016). Pengaruh Media Pembelajaran Berbasis Multimedia Terhadap Motivasi dan Hasil Belajar Materi Sistem Pencernaan Manusia Studi Eksperimen Pada Siswa Kelas V MI Miftahul Huda Pandantoyo. Dinamika Penelitian, 63.

Luk Luk Nur Mufidah. (2017). Memahami Gaya Belajar Untuk Meningkatkan Potensi Anak. Martabat $\square$ : Jurnal Perempuan dan Anak, 1(2): 246-259.

Moleong, L., J. (2013). Metode Penelitian Kualitatif. Bandung: PT. Remaja Rosdakarya.

Multimedia, Pengembangan, Pembelajaran Tematik, Sekolah Dasar, Berbasis Budaya, and Lokal Masyarakat. (2017). Pengembangan Multimedia Pembelajaran Tematik Sekolah Dasar Berbasis Budaya Lokal Masyarakat Flores. Jurnal Pendidikan Dasar Nusantara, 2(3): 151-162.
Nawawi. (2018). Mendesain Pembelajaran Efektif Berdasarkan Model ASSURE. 1: 1302-1307.

Phillips, R. (1997). The Developer's Handbook to Interactive Multimedia: A Practical Guide for Educational Applications. London: Kogan Page.

Pribadi. (2011). Model ASSURE Untuk Mendesain Pembelajaran Sukses. Jakarta: Dian Rakyat.

Rasidi, Tessa Qoriah. (2016). Implementasi Desain Pembelajaran ASSURE Model Pada Mata Pelajaran PAI. Atthulab, 1(2): 32. https://dspace.ups.edu.ec/bitstream/12 3456789/5224/1/UPS-QT03885.pdf.

Saihu. (2019). Pendidikan Karakter Berbasis Kearifan Lokal (Studi di Jembrana Bali). Edukasi Islami: Jurnal Pendidikan Islam, 08(01).

Syahril, S. (2018). Pengembangan Desain Model ASSURE Pada Pembelajaran IPS SD/MI." Tarbiyah al-Awlad (2018):

65-75. https://ejournal.uinib.ac.id/jurnal/index .php/alawlad/article/view/1592.

Taufik, Ahmad, Universitas Wahid, and Hasyim Semarang. (2019). Implementasi Pembelajaran Fikih Berbasis Multimedia Interaktif MacroEnabled Untuk Meningkatkan Keaktifan Siswa. Syamil, 7(2.

Technische Universtität München, LudiwgMaximilians-Universität München. (2018). Upaya Meningkatkan Hasil Belajar Ipa Melalui Penerapan Media Pembelajaran Berbasis Multimedia Peserta Didik. e-conversion - Proposal for a Cluster of Excellence.

Wahyudi, Nanang Gesang, Sri Anitah, and Muhammad Akhyar. (2016). Pengembangan Multimedia Pembelajaran Berbasis Adobe Flash Pada Mata Pelajaran PAI Kelas V di SDIT Al-Hasna Klaten. TEKNODIKA, 
16(01): 10-21.

Widia Maya Sari, Endang Susiloningsih.

(2015). Penerapan Model ASSURE Dengan Metode Problem Solving Untuk Meningkatkan Keterampilan Berpikir Kritis. 9(1): 1468-1477. 
